\title{
The Design and Optimization of the Multi-Energy Coupling System
}

\author{
Maowei Zhu ${ }^{1, \text { a }}$ \\ ${ }^{1}$ School of the North China Electric Power University, Baoding 071000, China; \\ a1076665449@qq.com
}

Keywords: the Multi-Energy, Coupling System, CHP, electric car, optimization model

\begin{abstract}
This paper firstly gives the scheme of the Multi-Energy Coupling System (MECS), which can be applied to college campuses. On the basis of the traditional Combined Cooling Heating and Power System (CCHP), we add solar photovoltaic and electric car into the MECS. Secondly, we establish the mathematical models of the main components in the MECS, including the solar photovoltaic system, the gas engine, the boiler, the lithium bromide refrigerator, the electric refrigerator and the electric car. Finally, we establish an optimization model with the object of minimum cost to help operating the Multi-Energy Coupling System.
\end{abstract}

\section{Introduction}

The Combined Cooling, Heating and Power system(CCHP), which integrates power generation, cooling and heating, is a type of total energy system on the basis of energy cascade utilization principle.

At present, China's energy supply mainly depends on fossil fuels, which are unsustainable and have caused serious pollution. Solar photovoltaic (pv), as a clean and renewable energy, is not suitable for large-scale use because of its low energy flow density. Combined CCHP systems[1] and solar power, on the one hand can reduce unrenewable energy consumption, on the other hand can make up the shortcomings of solar power's discontinuity and unstability.

Moreover, electric cars replacing the present cars which are mostly powered by gasoline fuels is an irreversible trend. This will bring great influence to power grid. When the power battery's remaining power is insufficient, electric cars absorb power from the power grid. When the electric car has plenty of power, in order to obtain higher economic efficiency, the owner will allow the electric car connecting to the power grid and supplying electric power to it. Joining electric cars, can not only greatly reduce the amount of system's electricity generation adevice nd energy storage device, reducing system operating costs, and can alleviate the pressure of the grid.

This paper combines traditional CCHP system with solar photovoltaic power generation and electric vehicles, designing a kind of Multi-Energy Coupling System(MECS). On this basis, established the mathematical models of the key devices of the Multi-Energy Coupling System (MECS), and also establish the optimization model to optimize the operation of the system output configuration.

\section{Design Scheme}

The MECS is connected to the power grid through distribution transformer. The distributed power supply system consists of photovoltaic, gas turbine and the corresponding configuration has generator, turbine-direct combustion $\mathrm{LiBr}$ absorption unit, the electric car. System with cooling load (including electric refrigeration load and the cooling load of $\mathrm{LiBr}$ refrigeration unit), heat load (including the heat load for heating and hot water supply), electricity load (including important pure electricity load, general pure electric load and electric refrigeration load). System of gas turbine and the turbine-direct combustion $\mathrm{LiBr}$ absorption unit[2] constitute the CCHP system. Electric load can be supply by three directions: when the light is enough, it can be supplied by photovoltaic system, excess electricity can be transported to electric vehicles or power grid; when light is insufficient, it can be supplied by both 
the MECS and the power grid, which ensures the reliability of power supply. Electric cars can be either as an energy storage unit, and can be as a distributed power supply.

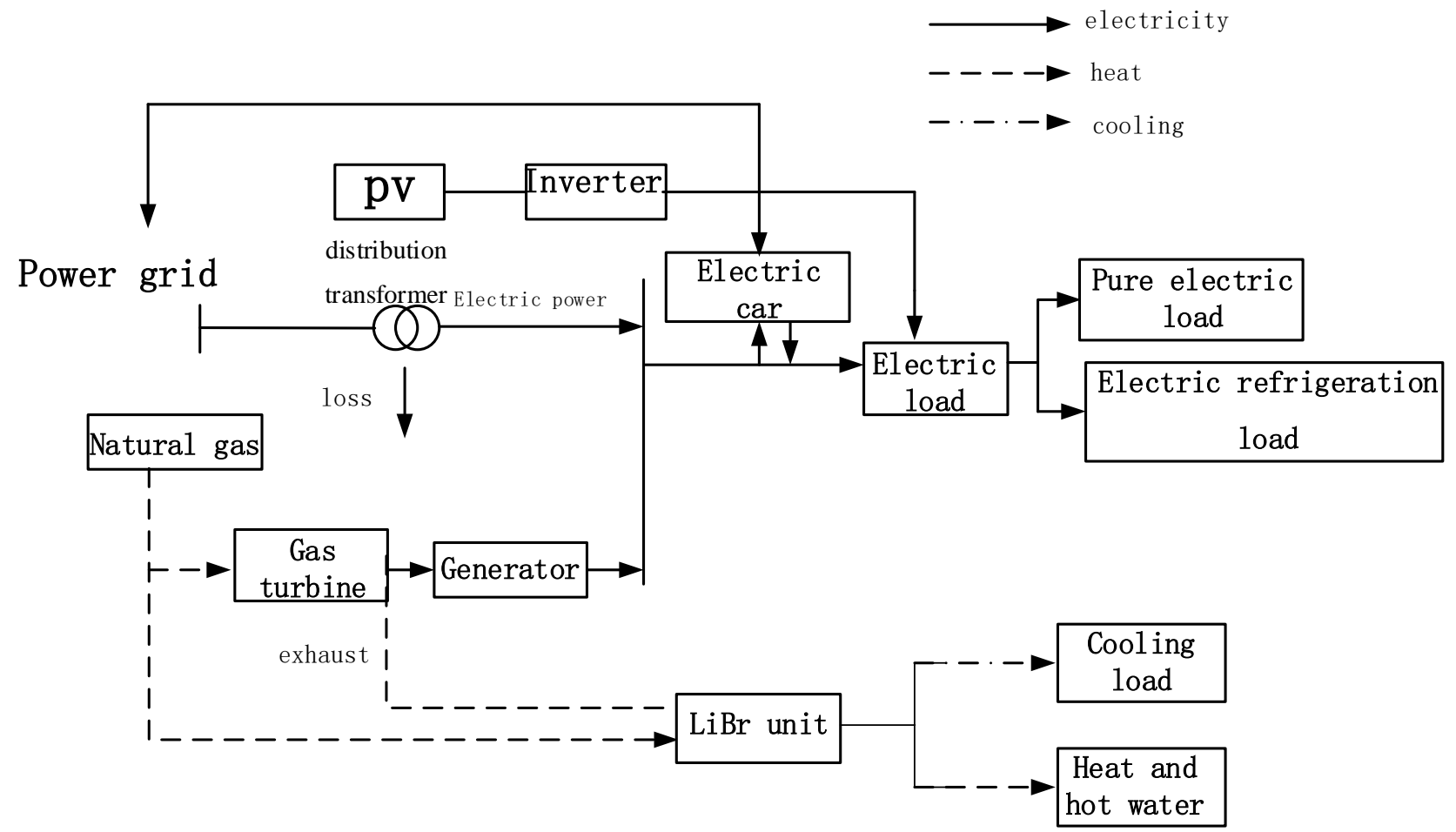

Figure 1 energy flow relations in MECS

The MECS use double bus power supply, since the gas turbine outlet voltage is $380 \mathrm{kV}$, it can supply the load directly. Flue gas $\mathrm{LiBr}$ unit can supply cycle through a pipeline to the teaching building and dormitory. Photovoltaic (pv) power generation system can need not set up line to supply load because it is close to the load, and the excess supply of electricity can be provided to electric cars or power grid through lines.

\section{System Modeling}

Photovoltaic power generation system. Because of the influence of sunlight intensity and temperature, there is large fluctuation of the photovoltaic power system's output . the output of the pv power calculation is as follows:

$$
\begin{gathered}
P_{p v}=f_{1}(G, T)=P_{s t c} * \frac{G(t)}{G_{s t c}}\left[1+k\left(T(t)-T_{s t c}\right)\right] \\
\left(T(t)=T_{e n v}+30 * \frac{G(t)}{1000}\right)
\end{gathered}
$$

Where $G(t) 、 T(t)$ respectively represent the actual sunlight intensity and temperature. $k$ is the power temperature coefficient.

Micro gas engine. In this paper, we choose C65 micro gas engine to establish the Multi-Energy Coupling System(MECS). Function relationship between C65 micro gas engine's power generation efficiency and output :

$$
\eta_{M T}=0.0753 \times\left(\frac{P_{M T}}{65}\right)^{3}-0.3095 \times\left(\frac{P_{M T}}{65}\right)^{2}+0.4174 \times\left(\frac{P_{M T}}{65}\right)+0.1068
$$

Where $\eta_{M T} 、 P_{M T}$ respectively represents C65 micro gas engine's power generation efficiency and output.

Therefore, the fuel consumption of natural gas and flue gas residual heat can be expressed as:

$$
V_{M T}=f_{2}\left(P_{M T}\right)=\frac{P_{M T}(t) \times \Delta t}{\eta_{M T}(t) \times L H V} \quad Q_{M T}=f_{3}\left(P_{M T}\right)=\frac{P_{M T}\left(1-\eta_{M T}(t)\right)}{\eta_{M T}(t)}
$$


Where $V_{M T}$ is the fuel consumption of natural gas; $Q_{M T}$ is the flue gas residual heat.

Boiler. Heating gas boiler's heating load and calculation of quantity of consumption of natural gas is as follows:

$$
Q_{b}=R_{b} \times \eta_{b} \quad V_{b}=f_{4}\left(Q_{b}\right)=\frac{Q_{b}(t) \times \Delta t}{\eta_{b}(t) \times L H V}
$$

Where $Q_{b}$ is the heating load; $\eta_{b}$ is the heating efficiency; $V_{b}$ is the consumption of natural gas.

The lithium bromide refrigerator and the electric refrigerator. The lithium bromide refrigerator's $C O P: C O P_{A R}=\frac{Q_{A R}}{Q_{h}+E} \approx \frac{Q_{A R}}{Q_{h}}$

Where $C O P_{A R}$ is the cooling coefficient of the lithium bromide refrigerator; $Q_{A R}$ is the refrigerating capacity. $Q_{h}$ is the flue gas residual heat.

The the electric refrigerator's COP: $C O P_{E R}=\frac{Q_{E R}}{E_{E R}}$

Where $C O P_{E R}$ is the cooling coefficient of the electric refrigerator; $Q_{E R}$ is the refrigerating capacity. $E_{E R}$ is the electic consumption.

Electric vehicles. SOC is the ratio of battery remaining power and battery capacity. Usually put a full battery under the condition of a certain temperature, the SOC of the battery is defined as $100 \%$.And let the battery is put electricity, the SOC of the battery is $0 \%$.

$$
S O C=\frac{E_{s}}{E_{b a t}}=1-\frac{\int I \mathrm{~d} t}{E_{\text {bat }}}
$$

Where $E_{s}$ is the remaining power, $E_{b a t}$ is the battery capacity. $I$ is the discharging current.

\section{The Optimization Model}

Considering from the angle of load demand, the MCES system's running goal, is to minimize the cost on the basis of meeting the demand of electric power, cooling and heating. The objective function is as follows[3]:

$$
\min E=p_{N G} \times V_{M T}+p_{N G} \times V_{b}+p_{1} \times P_{E V}+p_{2} \times P_{\text {grid }}
$$

Where $E$ stands for the cost; $p_{N G}$ is the price of the natural gas; $P_{E V}$ is the power that electric vehicles transmit to the MCES system; $P_{\text {grid }}$ is the power that the power grid transmits to the MCES system.

In actual operation, the MCES system's constraints are as follows:

The characteristic relationship of the solar photovoltaic system ,the gas engine, the boiler, the lithium bromide refrigerator, the electric refrigerator and the electric car:

$$
\begin{gathered}
P_{p v}=f_{1}(G, T) \quad V_{M T}=f_{2}\left(P_{M T}\right) \\
Q_{M T}=f_{3}\left(P_{M T}\right) \quad V_{b}=f_{4}\left(Q_{b}\right) \\
C O P_{A R} Q_{h}=Q_{A R} \quad C O P_{E R} g E_{E R}=Q_{E R}
\end{gathered}
$$

Capacity restraints:

$$
\begin{gathered}
P_{M T} \leq P_{M T R} \quad Q_{b} \leq Q_{b R} \\
Q_{A R} \leq Q_{A R R} \quad Q_{E R} \leq Q_{E R R} \\
P_{E V \text { min }} \leq P_{E V}(t) \leq P_{E V \max } \quad S O C_{E V \text { min }} \leq S O C_{E V}(t) \leq S O C_{E V \text { max }}
\end{gathered}
$$

Power balancing equations:

$$
\begin{gathered}
P_{M T}+P_{E V}+P_{g r i d}+P_{p v}-E_{l}-E_{E R}=0 \\
Q_{M T}+Q_{b}-Q_{l}-Q_{h}=0
\end{gathered}
$$




$$
Q_{A R}+Q_{E R}-C_{l}=0
$$

\section{Conclusion}

This paper firstly gives the scheme of the Multi-Energy Coupling System(MECS), which can be applied to college campuses. On the basis of the traditional Combined Cooling Heating and Power System (CCHP), we add solar photovoltaic and electric car into the MECS. Secondly, we establish the mathematical models of the main components in the MECS, including the solar photovoltaic system, the gas engine, the boiler, the lithium bromide refrigerator, the electric refrigerator and the electric car. Finally, we establish an optimization model with the object of minimum cost to help operating the Multi-Energy Coupling System.

\section{References}

[1] Chang Chen. (2009). Based on renewable energy has three cold heat electric heating power cycle characteristics research [D] (Doctoral dissertation, huazhong university of science and technology).

[2] Jing has printed, crane, \& jian-liang zhang. (2012). Solar heating and electrical installations, the multi-objective optimization design of the system and operation strategy analysis. Proceedings of the csee, 32 (20), 82-87.

[3] Wang, J., Zhai, Z. J., Zhang, C., \& Jing, Y. (2010). Environmental impact analysis of BCHP system in different climate zones in China. Energy, 35(10), 4208-4216. 